\title{
Nested Stromal-Epithelial Tumor of the Liver: A Review
}

\author{
Bita Geramizadeh \\ Department of Pathology, Shiraz University of Medical Sciences, Shiraz, Iran; \\ Transplant Research Center, Shiraz University of Medical Sciences, Shiraz, Iran
}

\section{Keywords}

Nested stromal-epithelial tumor · Review

\begin{abstract}
Background: Nested stromal-epithelial tumor (NSET) is a rare liver tumor, which is most commonly seen in the pediatric age group. To the best of our knowledge, there has been no published review on this rare tumor in the English literature so far. Summary: In this review, we will discuss all the reported details of the published cases, including demography, clinical presentation, molecular histogenesis, imaging, gross pathology and histopathology, immunohistochemical findings, treatment modalities, and outcome of NSET of the liver. Key Message: Thirty-eight cases of NSET have been reported in the last 20 years in the English literature. This tumor produces a very large and calcified mass in the liver and characteristically can present as Cushing syndrome. NSET is a nonbiliary and nonhepatocytic tumor with biphasic differentiation into 2 components of epithelial and stromal cells. The epithelial cells are arranged as nests of mildly atypical epithelial cells with a few mitotic figures. The stromal component is composed of myofibroblasts and desmoplastic stroma which often shows ossification and calcification. Immunohistochemically, this tumor is positive for both epithelial and mesenchymal markers. The majority of the reported cases in the literature had benign behavior with an indolent course.

(c) 2019 S. Karger AG, Base
\end{abstract}

\section{Introduction}

Improvements in diagnostic modalities result in the detection of more novel tumors. One of these tumors, which is still not very familiar to most of the pathologists, is characterized by both epithelial and mesenchymal differentiation [1]. This rare primary hepatic tumor 
shows a nesting morphology and variable degrees of calcification and/or ossification. This nonhepatocytic, nonbiliary primary liver neoplasm was first described by Heywood et al. [1] in 2002 [2].

After the initial definition, rare case reports and small case series have been published with different names, such as "desmoplastic nested spindle cell tumor (DNSTL)," "nested stromal-epithelial tumor (NSET)," and "calcifying nested stromal epithelial tumor (CNSET)" [1-23].

In this review, we will investigate published cases of this tumor in the English literature and will discuss the detailed characteristics of the clinical and paraclinical presentations, molecular and immunohistochemical characteristics, treatment, surgery, and follow-up as well as outcome.

\section{Methods}

Published case reports and case series in the English literature have been collected by searching in PubMed, Google, and Google scholar in the last 20 years.

The keywords for searching were "liver" and different names of the tumor, i.e., "calcifying stromal epithelial tumor," "nested stromal epithelial tumor," "desmoplastic nested spindle cell tumor," "ossifying stromal epithelial tumor," "mixed epithelial and stromal tumor," "nested epithelial tumor," "stromal and epithelial tumor of the liver," "desmoplastic stromal and epithelial tumor," and "desmoplastic mixed stromal and epithelial tumor." Thirty-eight cases were found in the English literature. Table 1 shows the clinical characteristics of these 38 cases.

\section{Demographic Findings}

The tumor is more common in female patients: 27 patients were female and only 11 cases were male (female $/$ male $=27 / 11)$. The age range was 22 months to 32 years $(14.6 \pm 9.7$ years). The tumor is significantly more common in children because 28 cases $(74 \%)$ were younger than 18 years.

\section{Clinical Presentation}

The presenting clinical signs and symptoms are nonspecific. Abdominal pain and discomfort are the most common presentations in patients with NSET of the liver; however, many of the previously reported cases were incidentally detected during imaging studies due to irrelevant causes. Among the 38 reported cases, 11 patients were asymptomatic, and the tumor was detected incidentally (28\%). An important potential presenting sign of this rare tumor is Cushing syndrome. Thirteen patients (34.2\%) presented with Cushingoid face and cheek swelling, weight gain, with or without hypertension, none of which had an adrenal mass or any other source of adrenocorticotropic hormone or cortisol [2, 4, 5, 7-13]. Other nonspecific and rare presentations are weight loss [7, 13], constipation [7], intestinal obstruction [5], fever [14], and nausea [4].

\section{Histogenesis and Molecular Pathogenesis}

NSET is a tumor with differentiation toward 2 components of stromal and epithelial lineages [1]. The histogenesis is still unknown and uncertain; however, there are theories regarding an origin from progenitor cells with potential for multi-phenotypic differentiation 
Table 1. Frequency of positive markers in the tissue of NSET of the liver according to the number of cases which have been tested in 2 epithelial and mesenchymal components ${ }^{\mathrm{a}}$

\begin{tabular}{|c|c|c|}
\hline Marker & $\begin{array}{l}\text { Frequency of positivity in } \\
\text { epithelial component }\end{array}$ & $\begin{array}{l}\text { Frequency of positivity in } \\
\text { mesenchymal component }\end{array}$ \\
\hline Cytokeratin (AE1/AE3) & $38 / 38(100 \%)$ & $38 / 38(100 \%)$ \\
\hline Cytokeratin (CAM5.2) & $7 / 8(87.5 \%)$ & $1 / 8(12.5 \%)$ \\
\hline CK7 & $10 / 27(37 \%)$ & $1 / 27(3.7 \%)$ \\
\hline CK19 & 9/19 (47.3\%) & $0 / 19$ \\
\hline CK20 & $0 / 8$ & $0 / 8$ \\
\hline CK8 & $5 / 6(83.3 \%)$ & $0 / 6$ \\
\hline CK18 & $6 / 9(66.7 \%)$ & $1 / 9(11.1 \%)$ \\
\hline CK5/6 & $2 / 2(100 \%)$ & $0 / 2$ \\
\hline Adrenocorticotropic hormone & $7 / 18(38.9 \%)$ & $7 / 18(38.9 \%)$ \\
\hline Vimentin & $16 / 24(66.7 \%)$ & $22 / 24(91.7 \%)$ \\
\hline Wilm's tumor-1 (nuclear) & $27 / 29(93.1 \%)$ & $27 / 29(93.1 \%)$ \\
\hline CD117 & $12 / 24(50 \%)$ & $13 / 24(54.1 \%)$ \\
\hline CD56 & $17 / 21(81 \%)$ & $17 / 21(81 \%)$ \\
\hline CD99 & $2 / 18(11.1 \%)$ & $2 / 18(11.1 \%)$ \\
\hline CD10 & $2 / 2(100 \%)$ & $2 / 2(100 \%)$ \\
\hline Desmin & $0 / 19$ & $0 / 19$ \\
\hline$\beta$-Catenin and E-cadherin & $3 / 3(100 \%)$ & $3 / 3(100 \%)$ \\
\hline Smooth muscle actin & $0 / 24$ & $18 / 24(75 \%)$ \\
\hline Neuron-specific enolase & $13 / 14(92 \%)$ & $13 / 14(92 \%)$ \\
\hline Chromogranin & $0 / 21$ & $0 / 21$ \\
\hline Synaptophysin & $0 / 21$ & $0 / 21$ \\
\hline S100 & $0 / 25$ & $8 / 25$ (32\%) (focal, osteoid) \\
\hline HepPar-1 & $0 / 25$ & $0 / 25$ \\
\hline Glypican-3 & $0 / 7$ & $0 / 7$ \\
\hline$\alpha$-Fetoprotein & $0 / 12$ & $0 / 12$ \\
\hline Epithelial membrane antigen & $11 / 20(55 \%)$ & $0 / 20$ \\
\hline Carcinoembryonic antigen & $0 / 12$ & $0 / 12$ \\
\hline Progesterone receptor & $1 / 1(100 \%)$ & $1 / 10(10 \%)$ \\
\hline Estrogen receptor & $0 / 8$ & $0 / 8$ \\
\hline HMB-45 & $0 / 7$ & $0 / 7$ \\
\hline Thyroid transcription factor- 1 & $0 / 4$ & $0 / 4$ \\
\hline Inhibin & $0 / 9$ & $0 / 9$ \\
\hline Ki67 & $1-10 \%$ (in 6 cases) & $1-10 \%$ (in 6 cases) \\
\hline
\end{tabular}

NSET, nested stromal-epithelial tumor. ${ }^{\text {a }}$ Data derived from references 1-23.

[4]. The majority of the reported tumors were positive for Wilm's tumor-1 (WT-1) and CD56, which can be a clue to an origin from hepatic mesenchymal precursor cells [5, 19]. Another finding in a few case reports was decreased expression of E-cadherin as well as mutation in $\beta$-catenin. This finding, along with upregulation of genes such as SNAIL and TWIST, is in favor of epithelial-mesenchymal differentiation $[6,10]$.

Another reported finding is the occurrence of NSET in Beckwith-Wiedemann syndrome in 3 cases $[2,8,21]$. This can be regarded as an evidence for the presence of a genetic abnormality as a predisposing factor.

In a few patients with NSET, a history of oral contraceptive pill consumption has been reported $[6,8,15,17]$. However, this seems to be a random coincidence because estrogen/ progesterone were consistently negative, and there is no correlation with a hormonal pathogenesis in NEST [17]. 
Some authors have proposed an underlying genitourinary abnormality. Their evidence was based on the observation of a co-occurrence of this tumor in the liver of patients with renal nephroblastomatosis and hypoplastic kidney as well as hydronephrosis $[5,19]$.

\section{Laboratory Findings}

Most of the patients with NEST of the liver have normal laboratory findings, except for adrenocorticotropic hormone and cortisol in the cases with Cushing syndrome. Liver enzymes were normal in most of the previously reported cases, and only 6 patients $(15.7 \%)$ with elevated liver enzymes have been detected [7, 11, 12, 15-17]. In all of these patients with abnormal liver enzymes, the highest levels of enzymes were for $\gamma$-glutamyl transpeptidase and alkaline phosphatase, which were secondary to a mass effect and cholestasis.

In the majority of cases, tumor markers were measured, especially $\alpha$-fetoprotein and carcinoembryonic antigen, which were always normal. In some cases, CA19-9 was also tested and was normal. In rare patients, other tests were done, such as $\beta H C G$ [7], prolactin, and sex hormones. None of them showed elevated levels of any tumor markers [9].

\section{Imaging Studies}

In the majority of cases, 3 imaging modalities, including ultrasonography, computed tomography (CT) scan, and magnetic resonance imaging (MRI), were used for clarifying the details of tumor characteristics, including the size and extension of the tumor, before surgery [8]. Most of the reported tumors were large. Ten tumors (26.3\%) were so extensive that they occupied both the left and right lobes. Isolated left and right lobe involvement was reported

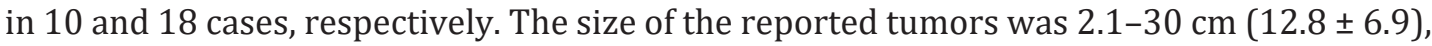
and more than $90 \%$ of the reported tumors were larger than $5 \mathrm{~cm}$. Therefore, typically, this type of tumor in the liver is a well-defined, nonencapsulated, large, multinodular and multilobulated mass.

Ultrasonography findings are nonspecific with solitary heterogeneous and mixed hypoand hyperechoic densities. Central necrosis is common [8]. CT scan of the tumor is mostly heterogeneous with central hypodensity [18] (Fig. 1). CT scan with contrast has also been reported as nonhomogeneous, with early enhancement in the arterial phase and washout in the portal and delayed phases [13].

Features of MRI have been reported as predominant T1 hypointensity and T2 hyperintensity $[17,18]$. In some cases with calcification, there was a susceptibility signal void with low T2 signal which blooms on gradient echo sequences [13]. When lesions are greater than $3 \mathrm{~cm}$, there is often a central scar, and they may contain calcification [19].

${ }^{11} \mathrm{C}$-choline positron emission tomography (PET) has also been reported in a few cases, with only slight pathological uptake of the tracer into the liver $[7,10,16,17,20]$. PET scan has been used mostly for the early diagnosis of disease progression and recurrence of this tumor [14].

Ossification and calcification on gross pathology and imaging are 2 very important diagnostic features in some of the cases with NSET, which have been reported in 8 (21\%) and 27 $(71 \%)$ cases, respectively. Central necrosis is not very common and has been reported in 6 $(15.7 \%)$ cases.

The main differential diagnoses in the imaging studies depend on the age of the patients and include fibrolamellar hepatocellular carcinoma, hepatoblastoma, calcified hemangioma, hemangioendothelioma, and hamartoma $[8,20]$. 


\section{Gastro \\ Intestinal \\ Tumors}

Fig. 1. Computed tomography scan without contrast of a case of nested stromal-epithelial tumor of the liver (arrows) with a mass in the right lobe.

Fig. 2. Biopsy of the mass shows adequate tissue with nested appearance of tumor cells (white solid arrow) and desmoplastic stroma (transparent arrow). HE, $\times 250$.

\begin{tabular}{l|l}
\hline Gastrointest Tumors 2019;6:1-10 \\
\hline DOI: 10.1159/000496339 & $\begin{array}{l}\text { @ 2019 S. Karger AG, Basel } \\
\text { www.karger.com/gat }\end{array}$ \\
\hline
\end{tabular}

Geramizadeh: Nested Stromal-Epithelial Tumor
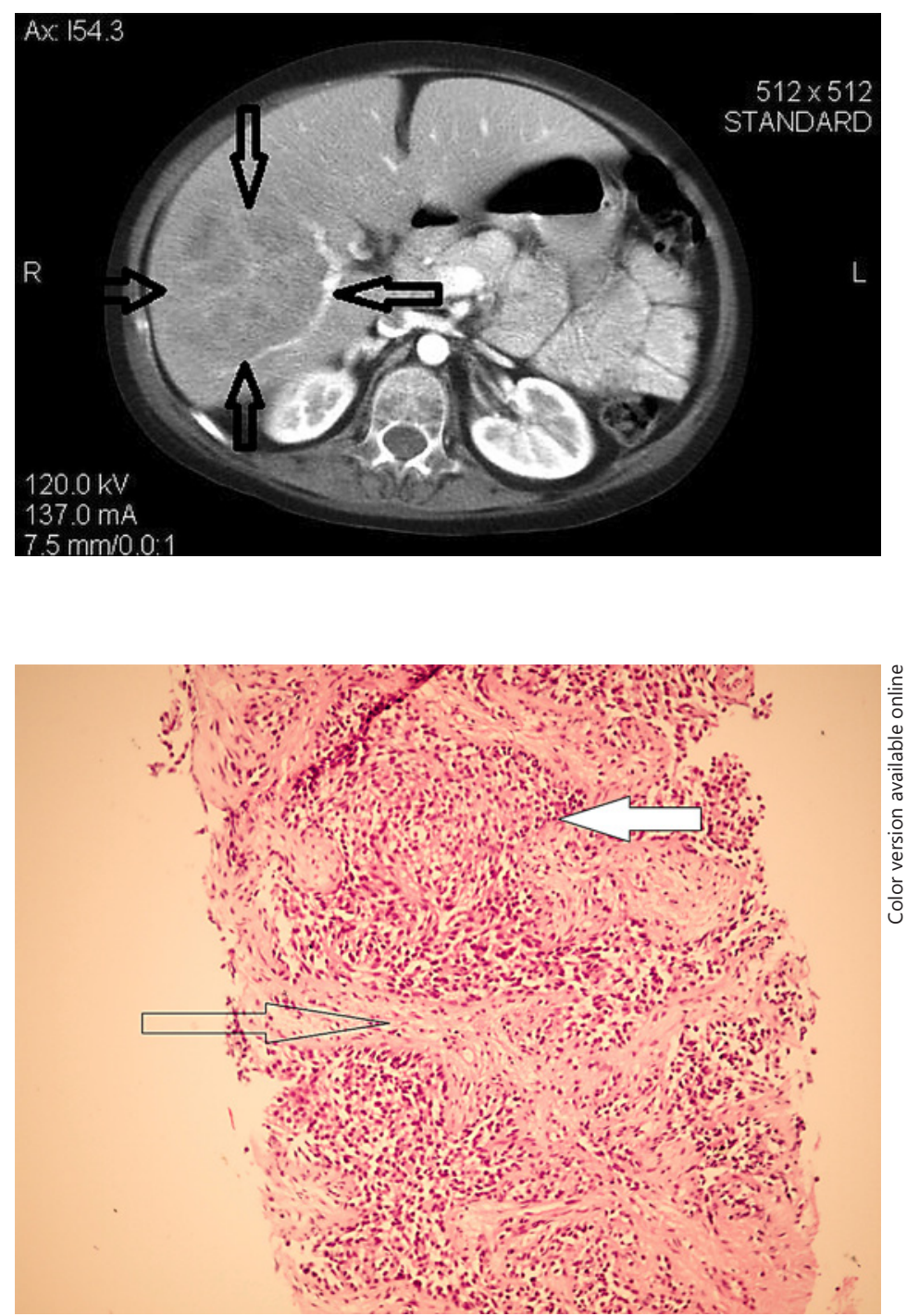

\section{Preoperative Tissue Biopsy}

Among the 38 reported cases, 12 patients had preoperative needle biopsies $[1,2,4,7,8$, 11, 12, 14, 18, 19, 23] (Fig. 2). Only 3 cases had a correct diagnosis based on the liver needle biopsy $[2,8,19]$, and all the other 9 cases were diagnosed as "unusual mixed tumor," "hepatoblastoma," "hamartoma," "neuroendocrine tumor," and "sarcoma" $[1,4,7,8,11,12,14,18$, 23].

\section{Pathologic Findings}

Gross findings in all of the 38 reported cases were very similar, i.e., all tumors were large, multilobular, and well demarcated with no capsule. The color of the tumor was creamy to white tan colored. The presence of necrosis, calcification, and ossification in the imaging studies was also confirmed in the gross pathology of NSET [7, 9, 15]. This tumor is most commonly solitary, but rarely satellite nodules have been reported in NSET [9] (Fig. 3). The 


\section{Gastro Intestinal Tumors}

Fig. 3. Gross pathology of the tumor shows a well-defined liver mass (arrows). Sections from the mass show typical desmoplastic stroma (arrow) and nests of intermediate-sized cells with mild atypia and low mitotic rate. No necrosis is present. HE, $\times 250$.

\begin{tabular}{l|l}
\hline Gastrointest Tumors 2019;6:1-10 \\
\hline DOI: 10.1159/000496339 & $\begin{array}{l}\text { @ 2019 S. Karger AG, Basel } \\
\text { www.karger.com/gat }\end{array}$ \\
\hline
\end{tabular}

Geramizadeh: Nested Stromal-Epithelial Tumor
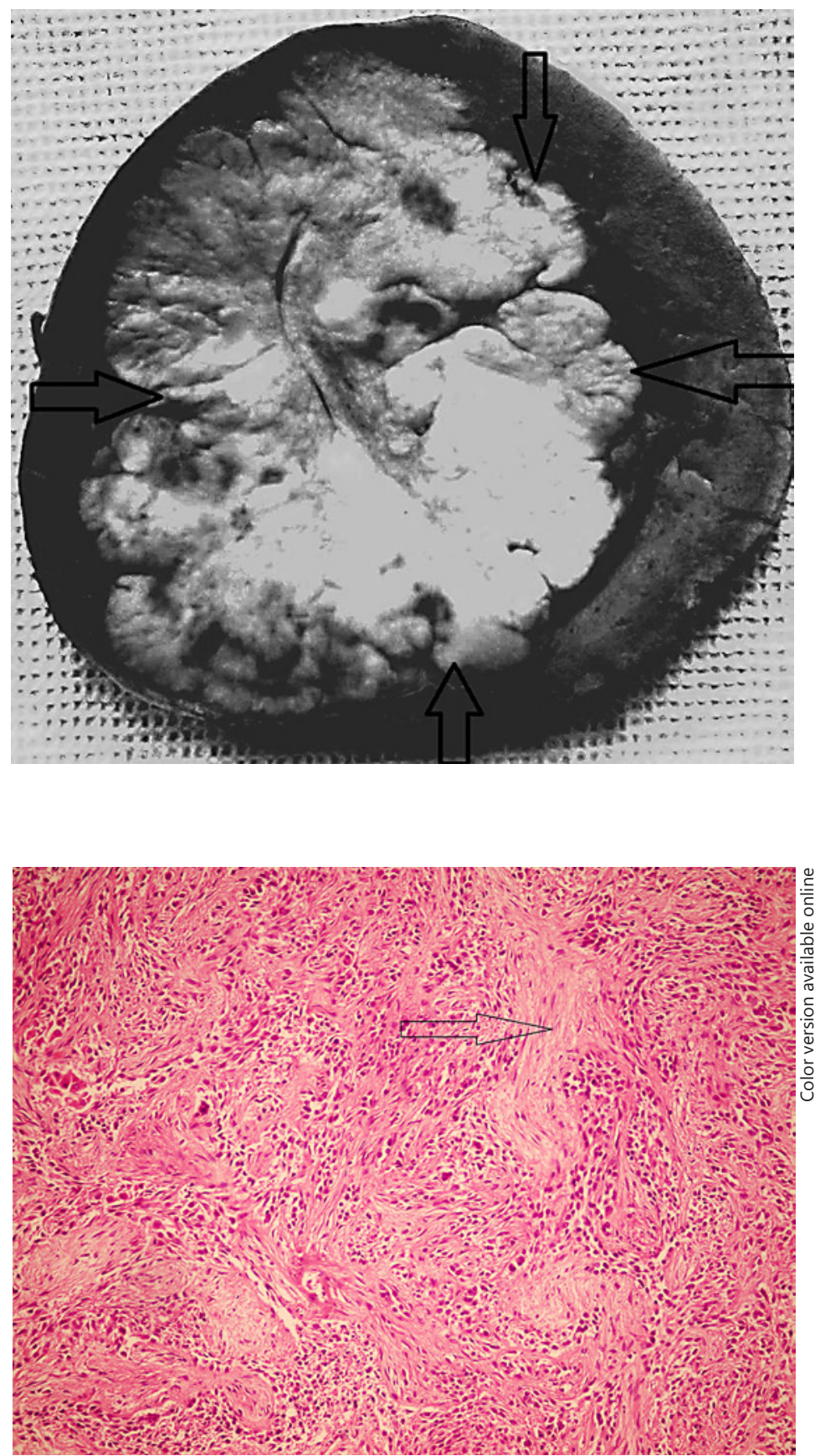

Fig. 4. Nests of tumor cells were strongly positive for cytokeratin (AE1/AE3). ×400. 


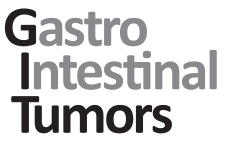

Fig. 5. CD56 was positive in the tumor. $\times 250$.

\begin{tabular}{l|l}
\hline Gastrointest Tumors 2019;6:1-10 \\
\hline DOI: 10.1159/000496339 & $\begin{array}{l}\text { @ 2019 S. Karger AG, Basel } \\
\text { www.karger.com/gat }\end{array}$ \\
\hline
\end{tabular}

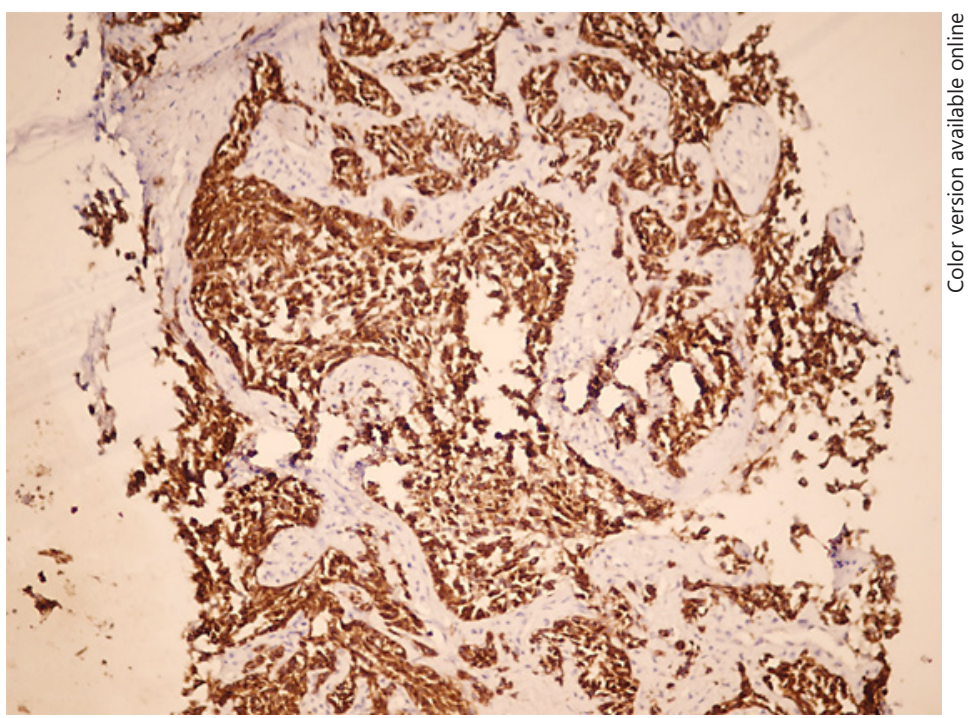

mucoid material have also been reported in some of the cases [22]. Entrapped mature bile ducts have been reported in the margin and within the bulk of the tumor [22].

In the high-power view, the epithelial cells show vacuolar clear or eosinophilic cytoplasm with little atypia. Severe atypia has not been reported. The nuclei are hyperchromatic without nucleoli or with inconspicuous nucleoli [6].

All of the previous tumors were mitotically active; however, the number of mitotic figures was completely variable from less than 1 per 10 high power fields (HPF) to more than 10 per $10 \mathrm{HPF}$. Only 1 of the previous cases showed atypical mitosis $[5,15,19]$.

Important issues regarding this tumor are predictors of aggressive behavior, recurrence, and metastasis. There is no definite predictor; however, it seems that larger size, presence of necrosis, sheet-like growth pattern, presence of satellite tumor nodules, vascular invasion, and atypical mitosis are important and should be mentioned in the report for closer followup and more aggressive treatment [2].

\section{Immunohistochemistry}

The majority of authors of the previously reported cases performed immunohistochemistry for a definite diagnosis and exclusion of other hepatic tumors. The results were more or less similar [1-23]. Table 1 shows the percentage of positivity and the cell location of the positive markers in the previous reports (Fig. 4, 5).

\section{Differential Diagnoses}

The histologic and immunohistochemical findings in NSET can be fairly informative for a pathologist being familiar with the entity. The most common and important differential diagnoses are: (1) Wilm's tumor: consistent positivity for WT-1 can be misleading to metastatic Wilm's tumor; however, typical aborted tubules of Wilm's tumor have not been reported in NSET [5]; (2) synovial sarcoma: co-expression of vimentin and epithelial markers can be an evidence of synovial sarcoma; however, the presence of calcification, ossification, and nests of epithelial cells as well as the absence of SYT-SSX fusion are all helpful to exclude 
Geramizadeh: Nested Stromal-Epithelial Tumor

Table 2. The most common characteristics of the published cases diagnosed as NSET of the liver ${ }^{\mathrm{a}}$

\begin{tabular}{ll}
\hline Characteristics & Most common finding \\
\hline Sex, female/male & $27 / 11$ \\
Age & 22 months to 32 years $(14.6 \pm 9.7$ years $)$ \\
Clinical presentation & Incidental, abdominal pain, Cushing syndrome \\
Imaging & Heterogeneous \\
Liver function tests & Normal \\
Tumor markers & Normal \\
Histological findings & Biphasic pattern with epithelial nests surrounded by myofibroblasts and calcification \\
Positive immunohistochemical markers & Cytokeratin, vimentin, Wilm's tumor-1, CK56 \\
Negative immunohistochemical findings & CD99, HepPar-1, chromogranin, synaptophysin \\
Behavior and outcome & Indolent \\
\hline
\end{tabular}

NSET, nested stromal-epithelial tumor. ${ }^{\text {a }}$ Data derived from references 1-23.

synovial sarcoma [22]; (3) desmoplastic small round cell malignant tumor can histologically mimic NSET; however, this tumor mostly occurs in young and adolescent men and has an aggressive behavior; it is consistently negative for EWS-WT1 (Ewing sarcoma-Wilm's tumor-1), which is always positive in desmoplastic small round cell malignant tumor [4]; (4) hepatocellular carcinoma can be excluded by the typical morphology and also negativity for HepPar-1 in NSET [4, 5, 22].

\section{Treatment}

In all of the reported cases, surgical excision of the tumor was performed; in 7 cases, the large size of the tumor prompted liver transplantation $[2,4,7-9,14,20]$. In the majority of cases, surgical excision was the treatment of choice; however, some patients also received postoperative chemotherapy $[4,5,7,22]$. Some of the patients received preoperative chemotherapy $[2,4,7,8]$. Postoperative ablation radiofrequency was also performed in some cases with favorable response both for the primary tumor and the recurrent tumor $[1,4]$.

In 1 case, preoperative chemotherapy was unsuccessful, and finally liver transplant was done [2]. In some cases, the patient received chemotherapy only after recurrence after resection $[5,14]$.

Chemotherapy has been similar to mixed epithelial and mesenchymal hepatoblastoma or sarcoma, including regimens consisting of cisplatin, doxorubicin, and ifosfamide or 5-fluorouracil and cisplatin $[5,7,22]$.

\section{Outcome and Follow-Up}

Of the 38 reported cases, all were alive at follow-up except for 3 patients who died. One of them died after surgery because of postoperative complications and sepsis [11], and another died after 5 years secondary to bilateral lung metastasis. She had undergone liver transplant because of recurrence and finally died 28 months after transplant [20]. The third case died because of multiple liver lesions [13]. Two other patients had recurrences after 12 and 168 months; however, both received chemotherapy and have survived [4,5]. One patient 
had bone and lymph node metastases after liver transplant with response to chemotherapy [14]. One patient was lost during follow-up [4].

All the other cases were alive and symptom free with no evidence of recurrence or metastases after $60 \pm 12.5$ months of follow-up [1-23].

\section{Conclusions}

NSET, also known as calcifying NSET, is a rare tumor which mostly occurs in the pediatric age group. The clinical presentation is not specific, and the tumor is mostly incidentally detected; however, some of these patients come to attention with Cushing syndrome. NSET has nonspecific imaging and characteristic histopathologic and immunohistochemical findings. The main characteristic of this tumor is a biphasic tumor pattern with 2 epithelial and stromal (mesenchymal) differentiations.

The clinical course of the disease is benign, and aggressive behavior and metastases are very rare. Table 2 shows a brief overview of the common characteristics of the published cases of NSET.

\section{Statement of Ethics}

The author has no ethical conflicts to disclose.

\section{Disclosure Statement}

This is to certify that the paper has not been published or has been under any consideration previously. It is the author's original work, and the author has no conflicts of interest.

\section{References}

1 Heywood G, Burgart LJ, Nagorney DM. Ossifying malignant mixed epithelial and stromal tumor of the liver: a case report of a previously undescribed tumor. Cancer. 2002 Feb;94(4):1018-22.

2 Khoshnam N, Robinson H, Clay MR, Schaffer LR, Gillespie SE, Shehata BM. Calcifying nested stromal-epithelial tumor (CNSET) of the liver in Beckwith-Wiedemann syndrome. Eur J Med Genet. 2017 Feb;60(2):136-9.

3 Misra S, Bihari C. Desmoplastic nested spindle cell tumours and nested stromal epithelial tumours of the liver. APMIS. 2016 Apr;124(4):245-51.

4 Makhlouf HR, Abdul-Al HM, Wang G, Goodman ZD. Calcifying nested stromal-epithelial tumors of the liver: a clinicopathologic, immunohistochemical, and molecular genetic study of 9 cases with a long-term follow-up. Am J Surg Pathol. 2009 Jul;33(7):976-83.

5 Heerema-McKenney A, Leuschner I, Smith N, Sennesh J, Finegold MJ. Nested stromal epithelial tumor of the liver: six cases of a distinctive pediatric neoplasm with frequent calcifications and association with Cushing syndrome. Am J Surg Pathol. 2005 Jan;29(1):10-20.

6 Wang Y, Zhou J, Huang WB, Rao Q, Ma HH, Zhou XJ. Calcifying nested stroma-epithelial tumor of the liver: a case report and review of literature. Int J Surg Pathol. 2011 Apr;19(2):268-72.

7 Assmann G, Kappler R, Zeindl-Eberhart E, Schmid I, Häberle B, Graeb C, et al. $\beta$-Catenin mutations in 2 nested stromal epithelial tumors of the liver-a neoplasia with defective mesenchymal-epithelial transition. Hum Pathol. 2012 Nov;43(11):1815-27.

8 Schaffer LR, Shehata BM, Yin J, Schemankewitz E, Alazraki A. Calcifying nested stromal-epithelial tumor (CNSET) of the liver: a newly recognized entity to be considered in the radiologist's differential diagnosis. Clin Imaging. 2016 Jan-Feb;40(1):137-9.

9 Brodsky SV, Sandoval C, Sharma N, Yusuf Y, Facciuto ME, Humphrey M, et al. Recurrent nested stromal epithelial tumor of the liver with extrahepatic metastasis: case report and review of literature. Pediatr Dev Pathol. 2008 Nov-Dec;11(6):469-73. 
10 Samarghandi A, Barker DW, Hingsbergen EA, Finegold MJ, Hall NC. CT, MRI and 18F-FDG PET/CT in a patient with nested stromal epithelial tumor of the liver. Clin Nucl Med. 2015;40(2):131-3.

11 Geramizadeh B, Foroutan H, Foroutan A, Bordbar M. Nested stromal epithelial tumor of liver presenting with Cushing syndrome: a rare case report. Indian J Pathol Microbiol. 2012 Apr-Jun;55(2):253-5.

12 Weeda VB, de Reuver PR, Bras H, Zsíros J, Lamers WH, Aronson DC. Cushing syndrome as presenting symptom of calcifying nested stromal-epithelial tumor of the liver in an adolescent boy: a case report. J Med Case Reports. 2016 Jun;10(1):160.

13 Meletani T, Cantini L, Lanese A, Nicolini D, Cimadamore A, Agostini A, et al. Are liver nested stromal epithelial tumors always low aggressive? World J Gastroenterol. 2017 Dec;23(46):8248-55.

14 Garg I, Baladron Zenetti MJ, Kendi AT. Nested stromal-epithelial tumor of liver with recurrent extrahepatic metastasis: role of Fluorodeoxyglucose positron emission tomography/computed tomography. Indian J Nucl Med. 2017 Oct-Dec;32(4):372-3.

15 Grazi GL, Vetrone G, d'Errico A, Caprara G, Ercolani G, Cescon M, et al. Nested stromal-epithelial tumor (NSET) of the liver: a case report of an extremely rare tumor. Pathol Res Pract. 2010 Apr;206(4):282-6.

16 Rod A, Voicu M, Chiche L, Bazille C, Mittre H, Louiset E, et al. Cushing's syndrome associated with a nested stromal epithelial tumor of the liver: hormonal, immunohistochemical, and molecular studies. Eur J Endocrinol. 2009 Nov;161(5):805-10.

17 Procopio F, Di Tommaso L, Armenia S, Quagliuolo V, Roncalli M, Torzilli G. Nested stromal-epithelial tumour of the liver: an unusual liver entity. World J Hepatol. 2014 Mar;6(3):155-9.

18 Oviedo Ramírez MI, Bas Bernal A, Ortiz Ruiz E, Bermejo J, De Alava E, Hernández T. Desmoplastic nested spindle cell tumor of the liver in an adult. Ann Diagn Pathol. 2010 Feb;14(1):44-9.

19 Meir K, Maly A, Doviner V, Gross E, Weintraub M, Rabin L, et al. Nested (ossifying) stromal epithelial tumor of the liver: case report. Pediatr Dev Pathol. 2009 May-Jun;12(3):233-6.

20 Hommann M, Kaemmerer D, Daffner W, Prasad V, Baum RP, Petrovitch A, et al. Nested stromal epithelial tumor of the liver-liver transplantation and follow-up. J Gastrointest Cancer. 2011 Dec;42(4):292-5.

21 Malowany JI, Merritt NH, Chan NG, Ngan BY. Nested stromal epithelial tumor of the liver in BeckwithWiedemann syndrome. Pediatr Dev Pathol. 2013 Jul-Aug;16(4):312-7.

22 Hill DA, Swanson PE, Anderson K, Covinsky MH, Finn LS, Ruchelli ED, et al. Desmoplastic nested spindle cell tumor of liver: report of four cases of a proposed new entity. Am J Surg Pathol. 2005 Jan;29(1):1-9.

23 Ghodke RK, Sathe PA, Kandalkar BM. Calcifying nested stromal epithelial tumor of the liver - an unusual tumor of uncertain histogenesis. J Postgrad Med. 2012 Apr-Jun;58(2):160-2. 